\title{
The greek version of the sense of coherence scale (soc-29): psychometric properties and associations with mental illness, suicidal risk and quality of life
}

\begin{abstract}
Background: Sense of coherence (SOC) is defined as a global orientation based on a person's confidence that stimuli are structured and predictable, the resources needed to meet these demands are available, and these demands are seen as challenges, worthy of investment, and engagement. The SOC scale is an instrument measuring how people manage stressful situations and stay well. We aimed to assess the psychometric properties of its Greek version in two samples, people with and without long-term conditions (LTCs). Associations between sense of coherence and mental illness, suicidality, and quality of life were also investigated.
\end{abstract}

Methods: The Antonovski's Sense of Coherence Scale (SOC-29) was administered to 374 participants; 245 patients with diabetes, chronic pulmonary obstructive disease and rheumatic diseases attending specialty clinics or the emergency department and 129 individuals without LTCs. Diagnosis of mental disorders was established by the Mini International Neuropsychiatric Interview. Associations with depressive symptom severity (PHQ-9), suicidal risk (RASS), and health-related quality of life (WHOQOL-BREF) were also investigated.

Results: The Greek version of SOC-29, when used as a whole, presented a coherent structure with remarkable stability in people with and without LTCs. Cronbach's alphas were 0.89 for patients with LTCs and 0.91 for people without LTCs, being 0.90 for the entire sample. Greater levels of SOC were associated with better mental health, lower depressive symptom severity and better quality of life. Furthermore, greater levels of SOC were associated with lower suicidal risk even after adjustment for depressive symptom severity.

Conclusion: The results of the present study showed that the Greek version of SOC-29 may reliably assess SOC. Moreover, lower levels of SOC are associated with established mental disorders and increased suicidal risk, and thus may detrimentally impact mental health. These findings may have important clinical implications, especially as far as the prevention of suicidal risk is concerned.

Keywords: sense of coherence, soc-29, chronic illness, mental illness, suicidality, quality of life
Volume 7 Issue 4 - 2017

\author{
Vassiliki Paika, Elisavet Ntountoulaki, Dimitra \\ Papaioannou, Thomas Hyphantis \\ Department of Psychiatry, Faculty of Medicine, School of Health \\ Sciences, University of loannina, Greece
}

Correspondence: Thomas Hyphantis, Professor of Psychiatry, Department of Psychiatry, Faculty of Medicine, School of Health Sciences, University of loannina, loannina 45। I0, Greece, Email tyfantis@cc.uoi.gr

Received: March 12, 2017 | Published: March 22, 2017
Abbreviations: LTCs, long-term conditions; DM, type-ii diabetes mellitus; RD, rheumatological disorders; COPD, chronic pulmonary obstructive disease; MDD, major depressive disorder; GAD, generalized anxiety disorder; SOC, sense of coherence; MINI, mini international neuropsychiatric interview; PHQ-9, patient; health questionnaire-9; RASS, risk assessment suicidality scale; HRQoL, health-related quality of life

\section{Introduction}

Thirty years ago, the medical sociologist Aaron Antonovsky introduced his salutogenic theory, in which adaptive coping is "the secret of movement toward the healthy end of the health ease/dis-ease continuum". ${ }^{1}$ Seeking a theoretical understanding of why "generalized resistance resources" such as wealth, ego strength, cultural stability, knowledge, commitment, magic, religion/philosophy or social support promoted health and "what did they have in common?" he concluded that the answer is the sense of coherence (SOC), ${ }^{2}$ shifting from the pathogenic focus on risk factors for disease to the salutogenic focus on the strengths and determinants for health. ${ }^{3}$ According to Antonovski, "resources were seen as leading to life experiences which promoted the development of a strong SOC, a way of seeing the world which facilitated successful coping with the innumerable, complex stressors confronting us in the course of living".
Sense of coherence is defined as a global orientation that expresses the extent to which one has a pervasive, enduring though dynamic feeling of confidence that

I. The stimuli deriving from one's internal and external environments in the course of living are structured, predictable, and explicable;

II. The resources are available to one to meet the demands posed by these stimuli; and

III. These demands are challenges, worthy of investment and engagement. ${ }^{2}$ It is a dispositional orientation rather than a personality trait/type or a coping strategy $y^{2,4}$ and its importance to a person's mental and physical health has been widely recognized in a number of studies and excellent reviews.

SOC has been found strongly related to perceived health, especially mental health; this relation was manifested regardless of age, sex, ethnicity, nationality, and study design, while SOC was able to predict health. ${ }^{5}$ SOC has been also found to have an impact on the quality of life; the stronger the SOC, the better the quality of life, and longitudinal studies confirm the predictive validity of the SOC for a good quality of life. ${ }^{6}$ Furthermore, a strong sense of coherence among older people was associated with better physical, social and mental health ${ }^{7}$ and low SOC could be a marker of risk for high suicidality in 
the aftermath of a suicide attempt. ${ }^{8}$ Finally, studies provide support for the clinical relevance of SOC in cancer patients ${ }^{9}$ with SOC having both a moderating and mediating effect on health (especially mental health and quality of life) in colorectal cancer patients, while preliminary data indicate that SOC may be an independent predictor of colorectal cancer patients survival. ${ }^{10}$

As research on SOC continues to grow, it is essential to have brief, reliable and valid assessment measures of SOC for a range of populations. The SOC scale has been translated across several different languages and used in several populations worldwide. A systematic review published in 2005 revealed that the SOC questionnaire has been used in at least 33 languages in 32 countries, with samples varying from large samples of the general population covering 20000 persons to small samples of 20 people. $^{3}$

The SOC scale has been translated in Greek and its test-retest reliability was estimated in a small sample with 22 persons and found $0.859 .{ }^{11}$ However, any additional information regarding the psychometric properties of the Greek version of SOC (e.g. factorial structure, internal consistency, or convergent validity) is lacking, possibly due to the small sample size. Prompted by this fact, and given that the study of the psychometric properties of SOC continues to grow $^{12-15}$ as additional studies in specific populations would provide a better appreciation of its psychometric potential, especially regarding its association with parameters that have attracted less attention such as suicidal risk in both health and disease, the aim of the present study was to examine the psychometric properties of the Greek version of the SOC-29 scale in two different samples:

a. Patients with long-term conditions (LTCs) attending specialty clinics or the emergency department (ED), and

b. People without LTCs. Furthermore, we aimed to assess its convergence and concurrent validity by analyzing associations with established mental disorders, depressive symptom severity, suicidal risk and health-related quality of life (HRQoL).

\section{Methods}

\section{Participants}

Data were collected during the baseline assessment of the cohort study "Assessing and enhancing resilience to depression in people with long term medical conditions in the era of the current Greek social and financial crisis". This research has been co-financed by the European Economic Area (EEA) Financial Mechanism 2009-2014 and National funds as part of the program "Dissimilarity, Inequality and Social Integration", and its main objective is to develop psychosocial strategies to enhance resilience to depression in most affected by the current Greek social and financial crisis vulnerable patients with LTCs, through a program of applied clinical research.

Of a total number of 505 adults participated in the study, 374 completed the RS-14 scale (response rate: $74.1 \%$ ) and thus were included in the present report. The sample comprised 245 patients with LTCs and 129 individuals without LTCs. The patient sample comprised patients with at least one of three LTCs: type-II diabetes mellitus (DM), rheumatological disorders (RD) and chronic pulmonary obstructive disease (COPD) who were seeking unscheduled or urgent care at the emergency department (ED) of the University Hospital of Ioannina or were attending routine care in the respective follow-up specialty clinics during a six-month period. These three conditions are among the leading 15 discharge diagnoses of emergency departments ${ }^{16}$ and are associated with an increased risk of an emergency hospital admission during the subsequent 6 month periods. ${ }^{17}$ Exclusion criteria were: inability to read and write Greek, mental retardation, active psychosis, state of intoxication or confusion, or being severely unwell physically to respond to the study's questionnaires.

Of 476 patients attending specialty clinics and the ED who were approached, 436 were eligible and 376 agreed to participate (response rate $79.0 \%$ ); 121 with DM only, 177 with RD only, 29 with COPD only and 49 with a combination of conditions. Ages ranged from 18 to 94 years (mean, 66.2; SD, 14.7); 136 were males (55.5\%) and 109 females $(44.5 \%)$. One-hundred and one patients did not complete the SOC-29 for certain reasons, mainly because they were severely unwell physically to complete all the study's instruments, or they left several items unanswered and were excluded from the present study, thus 245 patients were included in the analyses of the current study.

People without LTCs were recruited from the hospital staff. Healthcare workers in all hospital's departments and clinical units were invited to participate. Exclusion criterion was a self-reported LTC (i.e. DM, RD or COPD). Two hundred and twenty potential participants were approached, 200 were eligible and 129 agreed to participate (response rate $64.5 \%$ ). Ages ranged from 20 to 58 years (mean, 39.5; SD, 10.7); 32 were males $(24.8 \%$ ) and 97 females $(75.2 \%)$. No statistically significant differences were found in age, sex, education and marital status between participants and nonparticipants as well as between those who had completed the SOC-29 and those who did not provide complete responses to this instrument across all samples (data available upon request).

Researchers were in the hospital from 8.00 a.m. to 4.00 p.m. every day and participants were consecutively recruited during this time frame. Participants of either gender aged $\geq 18$ years old were considered for inclusion and, for patients, a diagnosis of DM, RD or COPD was confirmed by the attending physician. Three trained research psychologists (EN, VP, and DP) collected the data. The interviewers had at least 4years of research and clinical experience at the Department of Psychiatry of the University of Ioannina and were also trained on the administration of diagnostic instruments and screens. The interviewers were blind to scores of the self-report questionnaires, which were administered on the same day. All study procedures were in accordance with the World Medical Association Helsinki Declaration. The study was approved by the hospital's ethics committee (617/17-09-2015). Signed informed consent was obtained from all participants.

\section{Measures and study instruments}

Socio-demographic variables including age, sex, educational level, marital status, residence, employment status and occupation were collected for all participants. For patients with LTCs clinical features, disease severity indices and laboratory data were obtained from patients' records using a standardized data collection form. Coexisting medical diseases were scored using the Charlson comorbidity scale, ${ }^{18}$ which is one of the most extensively validated comorbidity indices.

Sense of coherence was assessed using the Greek translation of the Antonovski's sense of coherence scale. ${ }^{11}$ The Sense of Coherence (SOC) Scale is a 29-item questionnaire based on Aaron Antonovsky's salutogenic theory, and it is considered to be a measure of the stable dispositional orientation of a person, ${ }^{2,19}$ and it is essentially a measure of an individual's capacity to cope with stress. Those having high SOC scores are likely to perceive stressors as predictable and comprehensible and to perceive the challenges of life as meaningful and worth making commitments for, and, in addition, they have 
confidence in their capacity to manage. Respondents are asked to select a response, on a seven-point semantic differential scale with two anchoring phrases. There are 11 comprehensibility, 10 manageability and 8 meaningfulness items. Thirteen of the items are formulated 'negatively' and have to be reversed in scoring, so that a high score always expresses a strong SOC. ${ }^{2}$ The psychometric properties of the scale have been extensively tested in a number of studies across several samples and languages with Cronbach's alpha coefficients ranging from 0.70 to 0.95 , supporting the internal consistency reliability of the SOC. ${ }^{3}$

Diagnoses of mental disorders were established using the Greek version 5.0.0 of the Mini International Neuropsychiatric Interview (MINI) ${ }^{20}$ The MINI is a structured psychiatric interview that ascertains the diagnosis of mental disorders according to DSM-IV or ICD-10 criteria. ${ }^{21}$ It focuses mainly on current diagnosis and contains 120 questions for screening 17 axis I disorders. Being fully structured to allow administration by clinicians after a brief training session, it was designed to meet the need for a short but valid psychiatric interview for epidemiology studies. ${ }^{21}$ MINI has been previously used in studies with Greek medical patients..$^{22,23}$

Depressive symptom severity was assessed using the validated Greek version of the Patient Health Questionnaire-9 (PHQ-9). ${ }^{22,24}$ This instrument screens for DSM-IV major depressive disorder. The frequency of symptoms over the past 2 weeks is rated on a 0-3 Likert-type scale; summed scores range from 0 to 27 . Higher scores indicate more severe symptoms. It has been translated into numerous languages including Greek and is considered a valid measure of depressive symptom severity. ${ }^{22,25}$ Cronbach's alpha for PHQ-9 derived from the present sample was 0.83 .

Suicidal risk was assessed using the standardized Greek version of the Risk Assessment Suicidality Scale (RASS) ${ }^{26}$ RASS is a brief 12-item self-report instrument assessing suicidal risk behaviours and contains items relevant to intention, life, and history of suicide attempts. Items are rated on a 0-3 Likert-type scale (not at all to very much) and the scores were transformed according to the suggestions of the standardization study for use within the Greek population. ${ }^{26}$ In patients with LTCs attending the ED Cronbach's alpha for the RASS was 0.80 and alpha derived from the present sample was $0.77 .{ }^{27}$ Higher scores indicate greater suicidal risk.

Health-related quality of life (HRQoL) was assessed using the 26item validated Greek version of the World Health Organization Quality of Life Instrument, Short Form (WHOQOL-BREF). ${ }^{28}$ It assesses six domains of HRQoL, overall HRQoL, satisfaction with general health, physical, mental, social relations and environment HRQoL. Each item is rated on a 5-point Likert scale, and the scores are transformed on a scale from 0 to 100 . Higher scores indicate better HRQoL.

\section{Statistical analysis}

All analyses were performed using the Statistical Package for the Social Sciences (SPSS) version 21.0 (SPSS Inc., Chicago, IL, USA) for Windows. Summary statistics for all variables were calculated. Normality was tested by the Kolmogorov-Smirnov test. ${ }^{29}$ To test whether the SOC-29 items gather in clusters and to assess the stability of its factorial structure across the 2 samples, principal component factor analyses (PCA) with varimax rotation were performed separately for each sample as well as in the total sample. Internal consistencies (Cronbach alphas) were next calculated for the factors derived from the PCA.
The criterion and concurrent validity was tested with the following hypotheses in mind:

a. SOC is associated with health..$^{2,5,7}$ Accordingly, people without LTCs should present higher levels of SOC compared to medical patients. For this, two-tailed t-tests were carried out to assess the differences in SOC-29 scores between the two groups;

b. Sense of coherence is associated with mental health., $2,5,9,10$ Accordingly, SOC-29 score should be negatively associated with a diagnosis of mental disorder. For this, two tailed t-tests were performed to assess the differences in SOC-29 scores between those diagnosed with a mental disorder and those who didn't. To quantify the differences, simple logistic regression analyses were next performed with dependent variable the specific mental diagnosis and independent variable the SOC-29 score. In addition, to assess the relationship of SOC-29 with depressive symptom severity as assessed with the PHQ-9, bivariate correlation analyses were performed followed by partial correlation analyses adjusted for age, sex, education, family status, disease type and comorbidities;

c. SOC is associated with lower suicide risk. ${ }^{8}$ To assess the relationship between SOC-29 scores and RASS scores bivariate correlation analyses were performed followed by partial correlation analyses adjusted for age, sex, education, family status, disease type and comorbidities;

d. SOC is associated with better wellbeing, satisfaction with health and health-related quality of life. ${ }^{6}$ Accordingly, SOC-29 scores should be positively associated with WHOQOL-BREF scores. To test this, bivariate correlation analyses were performed followed by partial correlation analyses adjusted for age, sex, education, family status, disease type and comorbidities.

\section{Results}

\section{Factor structure}

Three independently produced principal component exploratory factor analyses were performed for the total sample and for each one group of participants, i.e. the participant without LTCs sample, and the medical patient sample. Principal component analyses across the three groups showed Kaiser-Mayer-Olkin statistics of 0.907, 0.853 , and 0.876 respectively; all Bartlett's tests were significant for sphericity $(\mathrm{x} 2=3369.2, \mathrm{df}=406, \mathrm{p}<0.001 ; \mathrm{x} 2=1626.0, \mathrm{df}=406$, $\mathrm{p}<0.001$; and $\mathrm{x} 2=2181.2, \mathrm{df}=406, \mathrm{p}<0.001$, respectively), supporting the factorability of the correlation matrices. An inspection of the screen plot in the total sample as well as in all the two groups of participants (data available upon request) revealed a large component and a number of "elbows" resulting in small eigenvalues after the fifth component, revealing the presence of a multidimensional structure. However, we concluded that the item loadings were scattered in the five factors and the analyses did not help identify any latent factor, i.e. the manageability, meaningfulness and comprehensibility theoretical dimensions of SOC, as the items representing these dimensions were present in each of these five factors. Given this and take also into consideration the Antonovski's warning that "the SOC scale is not wisely used to study component interrelations, as there is no basis for deriving distinguishable sub-scores for comprehensibility, manageability and meaningfulness", ${ }^{2}$ we repeated the factor analyses using the fixed number of factors to be extracted model, defining one factor to be extracted. 
Table I Factor loadings of the Greek version of the Sense of Coherence scale (SOC-29)

\begin{tabular}{|c|c|c|c|}
\hline & $\begin{array}{l}\text { Total Sample } \\
(\mathrm{N}=374)\end{array}$ & $\begin{array}{l}\text { Participants without LTCs } \\
(\mathrm{N}=129)\end{array}$ & $\begin{array}{l}\text { Patients with LTCs } \\
(\mathbf{N}=245)\end{array}$ \\
\hline $\begin{array}{l}\text { Item I - When you talk to people do you have the feeling that } \\
\text { they don't understand you? (Never have this feeling/Always have } \\
\text { this feeling) (R) }\end{array}$ & .466 & .502 & .438 \\
\hline $\begin{array}{l}\text { Item } 2 \text { - When you have to do something which depends on } \\
\text { co-operation with others, do you have the feeling that it: (Surely } \\
\text { won't get done/Surely will get done) }\end{array}$ & .420 & .544 & .366 \\
\hline $\begin{array}{l}\text { Item } 3 \text { - Think of the people with whom you come into contact } \\
\text { daily, aside from the ones to whom you feel closest. How well } \\
\text { do you know most of them? (You feel that they're strangers/You } \\
\text { know them very well) }\end{array}$ & .403 & .360 & .431 \\
\hline $\begin{array}{l}\text { Item } 4 \text { - Do you have the feeling that you don't really care about } \\
\text { what goes on around you? (Very seldom or never/Very often) } \\
\text { (R) }\end{array}$ & .444 & .535 & .395 \\
\hline $\begin{array}{l}\text { Item } 5 \text { - Are you surprised by the behaviour of people whom } \\
\text { you thought you knew well? (Never/Always) (R) }\end{array}$ & .398 & .346 & .403 \\
\hline $\begin{array}{l}\text { Item } 6 \text { - Has it happened that people whom you counted on } \\
\text { have disappointed you? (Never happened/Always happens) (R) }\end{array}$ & .411 & .378 & .406 \\
\hline Item 7 - Life is: (Full of interest /Completely routine) (R) & .574 & .594 & .548 \\
\hline $\begin{array}{l}\text { Item } 8 \text { - Until now your life has had: (No clear/very clear goals } \\
\text { and purpose) }\end{array}$ & .501 & .679 & .414 \\
\hline $\begin{array}{l}\text { Item } 9 \text { - Do you have the feeling that you are being treated } \\
\text { unfairly? (Very often/Very seldom or never) }\end{array}$ & .472 & .512 & .452 \\
\hline $\begin{array}{l}\text { Item I0 - In the past ten years your life has been: (Full of changes } \\
\text { without your knowing what will happen next /Completely } \\
\text { consistent and clear) }\end{array}$ & s. .341 & .334 & .343 \\
\hline $\begin{array}{l}\text { Item II - Most of the things that you do in future will probably } \\
\text { be: (Completely fascinating /Deadly boring) (R) }\end{array}$ & .497 & .565 & .436 \\
\hline $\begin{array}{l}\text { Item } 12 \text { - Do you have the feeling that you are in an unfamiliar } \\
\text { situation and don't know what to do? (Very often/Very seldom } \\
\text { or never) }\end{array}$ & .668 & .735 & .640 \\
\hline $\begin{array}{l}\text { Item I3 - What best describes how you see life: (One can always } \\
\text { find a solution/There is no solution to painful things in life) (R) }\end{array}$ & .532 & .591 & .494 \\
\hline $\begin{array}{l}\text { Item I } 4 \text {-When you think about life. you very often: (Feel how } \\
\text { good it is to be alive/Ask yourself why you exist at all) }\end{array}$ & .691 & .662 & .696 \\
\hline $\begin{array}{l}\text { Item I5 - When you face a difficult problem the choice of a } \\
\text { solution is: (Always confusing and hard to find/Always completely } \\
\text { clear) }\end{array}$ & $y .532$ & .617 & .488 \\
\hline $\begin{array}{l}\text { Item } 16 \text { - Doing things you do every day is: (A source of deep } \\
\text { pleasure and satisfaction/A source of pain and boredom) (R) }\end{array}$ & .632 & .596 & .649 \\
\hline $\begin{array}{l}\text { Item } 17 \text { - Your life in the future will probably be: (Full of changes } \\
\text { without your knowing what will happen next/Completely } \\
\text { consistent and clear) }\end{array}$ & .181 & .115 & .222 \\
\hline $\begin{array}{l}\text { Item I8 - When something unpleasant happens your tendency is: } \\
\text { ("To beat yourself up" about it/To say "ok. that's that. I have to } \\
\text { live with it", and go on) }\end{array}$ & .551 & .585 & .561 \\
\hline $\begin{array}{l}\text { Item } 19 \text { - Do you have very mixed up feelings and ideas? (Very } \\
\text { often/Very seldom or never) }\end{array}$ & .667 & .672 & .677 \\
\hline $\begin{array}{l}\text { Item } 20 \text { - When you do something that gives you a good feeling: } \\
\text { (It's certain that you'll go on feeling good/lt's certain that } \\
\text { something will happen to spoil the feeling) (R) }\end{array}$ & .617 & .479 & .662 \\
\hline $\begin{array}{l}\text { Item } 21 \text { - Does it happen that you have feelings inside which you } \\
\text { would rather not feel? (Very often/Very seldom or never) }\end{array}$ & .537 & .625 & .523 \\
\hline $\begin{array}{l}\text { Item } 22 \text { - You anticipate that your personal life in future will be: } \\
\text { (Totally without/Full of meaning or purpose) }\end{array}$ & .620 & .630 & .596 \\
\hline $\begin{array}{l}\text { Item } 23 \text { - Do you think that there will always be people whom } \\
\text { you'll be able to count on in the future? (You're certain there will } \\
\text { be/You doubt there will be) (R) }\end{array}$ & 11.374 & .474 & .319 \\
\hline
\end{tabular}


Table Continued...

\section{Total Sample Participants without LTCs Patients with LTC \\ $(\mathrm{N}=374)$ $(N=\mid 29)$ \\ $(\mathrm{N}=\mathbf{2 4 5})$}

Item 24 - Does it happen that you have the feeling that you don't know exactly what's about to happen? (Very often/Very seldom .463

or never)

Item 25 - Many people - even those with a strong character sometimes feel like losers in certain situations. How often do you feel this way? (Never/Very often) (R)

Item 26 - When something happened, have you generally found that: (You overestimated or underestimated its importance/You $\quad .427$ saw things in the correct proportion)

Item 27 - When you think of difficulties you are likely to face in important aspects of your life, do you have the feeling that: (You ${ }_{.565}$ will always succeed in overcoming the difficulties/You won't

succeed in overcoming the difficulties) (R)

Item 28 - How often do you have the feeling that there's little meaning in the things you do in your daily life? (Very often/Very .66I seldom or never)

Item 29 - How often do you have feelings that you're not sure you can keep under control? (Very often/Very seldom or never) $\%$ of Variance 37.5
.738

.588

40.5
.627

36. I

Table 2 Internal consistency coefficients and SOC total scores across the three samples

\begin{tabular}{llll}
\hline & Total Sample (N=374) & Participants without LTCs (N=I29) & Patients with LTCs (N=245) \\
\hline Internal Consistencies (Cronbach's alphas) & 0.9 & $0.9 \mid$ & 0.89 \\
\hline SOC Total score (mean \pm SD) & $137.3 \pm 25.9$ & $142.9 \pm 23.4 *$ & $134.3 \pm 26.7 *$
\end{tabular}

(*) asterisk indicate statistically significant difference at a $\mathrm{p}=0.002$ between participants without LTCs and patients with LTCs based on two-tailed t-test

Table 3 Sense of Coherence and Mental Illness in the Total Sample (N=374)

\begin{tabular}{|c|c|c|c|c|c|c|c|c|}
\hline \multirow[b]{2}{*}{$\begin{array}{l}\text { SOC-29 } \\
\text { Total Score }\end{array}$} & \multicolumn{2}{|c|}{ Any Mental Disorder } & \multicolumn{2}{|c|}{ Major Depression } & \multicolumn{2}{|c|}{ Panic Disorder } & \multicolumn{2}{|c|}{ Generalized Anxiety Disorder } \\
\hline & $\begin{array}{l}\text { Yes } \\
\text { e(N=|43) }\end{array}$ & $\begin{array}{l}\text { No } \\
(N=23 I)\end{array}$ & $\begin{array}{l}\text { Yes } \\
(N=73)\end{array}$ & $\begin{array}{l}\text { No } \\
(N=23 I)\end{array}$ & $\begin{array}{l}\text { Yes } \\
(N=19)\end{array}$ & $\begin{array}{l}\text { No } \\
(N=23 I)\end{array}$ & $\begin{array}{l}\text { Yes } \\
(N=53)\end{array}$ & $\begin{array}{l}\text { No } \\
(N=23 I)\end{array}$ \\
\hline $\begin{array}{l}\text { Mean } \pm \text { SD } \\
\text { (Two-tailed } \\
\text { t-tests) }\end{array}$ & $121.5 \pm 22.4$ & $147.0 \pm 23.0 * * *$ & $115.3 \pm 21.8$ & $147.0 \pm 23.0 * * *$ & $112.9 \pm 30.4$ & $147.0 \pm 23.0 * * *$ & $117.6 \pm 21.7$ & $147.0 \pm 23.0 * * *$ \\
\hline \multicolumn{3}{|c|}{ OR $(95 \% \mathrm{Cl}) 0.95(0.94 \mathrm{C}$} & \multicolumn{2}{|c|}{$0.94(0.926-0.956) * * *$} & \multicolumn{2}{|c|}{$0.97(0.949-0.984) * * *$} & \multicolumn{2}{|c|}{$0.95(0.930-0.962) * * *$} \\
\hline
\end{tabular}

OR: Odds Ratio; Cl: Confidence Interval;

$* * * p<0.001$.

Table 4 Sense of Coherence and Depressive Symptom Severity, Suicidal Risk, and Health-Related Quality of Life (HRQoL) (N=374)

\begin{tabular}{lll}
\hline & \multicolumn{2}{l}{$\begin{array}{l}\text { Sense of Coherence (SOC-29) } \\
\text { Correlation Coefficients }\end{array}$} \\
& Unadjusted & Adjusted \\
\hline Depressive Symptoms (PHQ-9) & $-0.572 * * *$ & $-0.530 * * *$ \\
\hline Suicidal Risk (RASS) & $-0.564 * * *$ & $-0.526 * * *$ \\
\hline HRQoL & & \\
\hline Overall HRQoL & $0.498 * * *$ & $0.467 * * *$ \\
\hline Satisfaction with General Health & $0.411 * * *$ & $0.344 * * *$ \\
\hline Physical HRQoL & $0.515 * * *$ & $0.476 * * *$ \\
\hline Mental HRQoL & $0.698 * * *$ & $0.652 * * *$ \\
\hline Social Relations HRQoL & $0.462 * * *$ & $0.427 * * *$ \\
\hline Environment HRQoL & $0.416 * * *$ & $0.418 * * *$ \\
\hline
\end{tabular}

Note:Values Shown are Bivariate Pearson Correlation Coefficients and Partial Pearson Correlation Coefficients Adjusted for Age, Sex, Education, Family Status, Number of Medical Illness ( 0 for Healthy Participants) and Comorbidities $* * * p<0.001$ 
As shown in Table 1, all but one items loaded saliently on this factor, with item loadings ranged between 0.341 and 0.691 in the total sample, confirming the coherent one-factor structure of this version of the instrument. Similar results were observed regarding the item loadings across the two sub-samples. The only exception was for item 17 ("Your life in the future will probably be: Full of changes without your knowing what will happen next/Completely consistent and clear") that presented lower loadings across all samples $(0.115-$ 0.222) (Table 1).

\section{Internal consistency, total scores and associations with demographics}

As shown in Table 2, Cronbach's alphas for the one-factor solution were 0.91 for the participant without LTCs sample and 0.89 for the medical patient sample, and alpha for the total sample was 0.90 . Mean scores of SOC-29 was lower for patients with LTCs compared to participants without LTCs $(\mathrm{p}=0.002)$ (Table 2). Females presented a trend towards lower SOC compared to males $(\mathrm{p}=0.079)$ while mean rates of SOC-29 did not differ significantly across marital status $(p=0.501)$; the stronger the sense of coherence the better the education received $(\mathrm{r}=0.236, \mathrm{p}<0.001)$, while older people tended to report lower SOC-29 scores, although the correlation coefficient failed to reach statistical significance $(\mathrm{p}=0.070)$.

\section{Resilience and mental illness}

One hundred and forty-three (38.2\%) participants were diagnosed with a mental disorder, $73(19.5 \%)$ with major depressive disorder (MDD), 19 (5.1\%) with panic disorder and 53 (14.2\%) with generalized anxiety disorder (GAD). As shown in Table 4, people diagnosed with any mental illness, either MDD, panic disorder or GAD, presented lower scores in SOC-29 compared to those without a mental disorder. The binary logistic regression analyses performed to quantify the differences confirmed these associations (Table 3 ).

\section{Sense of coherence and depressive symptom severity, suicidal risk, and HRQoL}

Table 4 presents the results of the unadjusted and adjusted (partial) correlation analyses performed to assess the associations of SOC29 with PHQ-9, RASS, and WHOQOL-BREF scores. As shown in this table, both unadjusted and adjusted scores of SOC-29 were significantly associated with depressive symptom severity, suicidal risk, and HRQoL. The higher the sense of coherence the lower the depressive symptom severity and the suicidal risk; also, the higher the sense of coherence the better the overall HRQoL, satisfaction with general health as well as the physical, mental, social relations and environment HRQoL.

In the further linear regression analyses performed separately for patients with LTCs and for people without LTCs with dependent variable the RASS score, SOC remained a significant correlate of suicidal risk even after depressive symptom severity was taken into account (Table 5).

Table 5 Linear Regression Analyses with Dependent Variable the Suicidal Risk (Rass) in People with and without Long-Term Conditions (LTCs)

\begin{tabular}{lllll}
\hline & \multicolumn{3}{l}{ Participants without LTCs (N= I29) } & \multicolumn{2}{l}{ Patients with LTCs (N=245) } \\
\hline & Beta & $\mathbf{P}$ & Beta & P \\
\hline Sense of Coherence (SOC) & -0.48 & $<0.00 I$ & $-0.20 I$ & $0.00 I$ \\
\hline Depressive Symptom Severity (PHQ-9) & 0.32 & $<0.00 I$ & 0.518 & $<0.00 I$ \\
\hline Age & 0.151 & 0.028 & -0.033 & 0.555 \\
\hline Sex & 0.09 & 0.157 & -0.077 & 0.115 \\
\hline Divorced/Widowed/Separated & -0.107 & 0.101 & -0.015 & 0.757 \\
\hline Education & -0.098 & 0.154 & -0.048 & 0.413 \\
\hline Adjusted R Square & 0.514 & & 0.457 & \\
\hline
\end{tabular}

\section{Discussion}

The results of the present study revealed that the one-dimensional use of the Greek version of SOC-29 showed a coherent structure with remarkable stability across the two samples studied, i.e. in people with and without LTCs. In terms of the factors' content, all items loadings were similar to its original version. Internal consistency coefficients were adequate across the samples and all indices of criterion and convergent validity were in the expected direction. Present findings support the validity of the SOC-29 for use within the Greek population.

The results of the studies assessing the factorial status of SOC are inconclusive. Some studies confirmed the one factor solution proposed by Antonofski, ${ }^{30,31}$ while others, similar to our findings, failed to support the one factor solution. ${ }^{32,33}$ A two, ${ }^{34}$ three $^{35}$ and five $^{36}$ factor solutions have been also proposed, but failed to actually support the theoretical construction principles which suggest three sub-dimensions.

namely manageability, meaningfulness and comprehensibility. Our findings and the results of previous studies indicate that it would be rather preferable to use the SOC scale as a measure of the whole, not examining the three subscales separately, which was also Antonovsky's intention. ${ }^{3}$ In this respect, our factor analysis defining one factor to be extracted revealed a coherent structure of the instrument with a remarkable stability when used in people with and without medical illnesses, with acceptable percentages of variance explained (36.1-40.5\%) and significant item loadings, $90 \%$ of them being greater than 0.40 and $60 \%$ greater than 0.50 . The coherent structure of the one factor solution is also supported by the high internal consistency coefficients observed (0.89-0.91). A systematic review on the validity of SOC found that in 124 studies using SOC-29 the Cronbach's a ranges from 0.70 to $0.95 .^{3}$

The criterion validity of the SOC-29 was supported in four ways. First, patients with LTCs presented lower levels of SOC compared to people without LTCs. In addition, people with mental disorders, either MDD, panic disorder or GAD presented lower SOC rates compared to those without a mental disorder. SOC was also negatively associated with depressive symptom severity. These findings indicate that SOC, as assessed by this version of the scale, is associated with both physical and mental health and are in accordance with the results of numerous previous studies performed. ${ }^{2,5,7,9,10}$ A systematic review including 458 scientific publications and 13 doctoral theses found that SOC was strongly related to perceived health, especially mental health, regardless of age, sex, ethnicity, nationality, and study design and it was able to predict health, and concluded that SOC is an important contributor for the development and maintenance of people's health ${ }^{5}$. 
By including patients with established medical illnesses and by using a structured psychiatric interview for reliably establishing mental diagnoses, our results support the relationship of SOC with physical and mental health, further confirming the available evidence.

Second, in line with the results of previous studies, higher levels of SOC were associated with better overall HRQoL and satisfaction with general health as well as with better HRQoL in all dimensions of WHOQOL-BREF, i.e., physical, mental, social relations and environment HRQoL, confirming our hypothesis. Erickson et al (2007) systematic review found that SOC has an impact on the quality of life; the stronger the SOC, the better the quality of life, while longitudinal studies confirm the predictive validity of the SOC for a good quality of life. ${ }^{6}$ Previous studies of our research group have also shown a strong association between SOC and HRQoL in patients with rheumatologic disorders ${ }^{37-40}$ and cancer. ${ }^{41-45}$

Third, similar to the findings of other studies reporting that men usually have a slightly higher SOC than women but the differences are small, ${ }^{3}$ we also observed a trend males to present higher levels of SOC compared to females $(\mathrm{p}=0.079)$. Despite, however, that studies have shown that SOC tends to increase with age over the whole life span, ${ }^{3}$ we found that older people tended to report lower SOC-29 scores, although this relationship failed to reach statistical significance $(p=0.070)$. We also found that greater SOC is associated with better education received. This is important, as evidence suggests that the SOC is applicable in learning processes and evaluation of education. An analysis of the similarities between the learning process and the salutogenic model has been reported, as the learning process is facilitated when the information is structured and comprehensible and thus becomes meaningful. ${ }^{6}$ It has been therefore suggested that integrating the salutogenic perspective in all activities and programmes in school also means that health promotion becomes integrated with school development. ${ }^{46}$

Finally, one of our main findings was that lower levels of SOC were associated with increased suicidal risk. It is worth noting that this relationship remained stable even after depressive symptom severity was taken into account, indicating that SOC is a strong correlate of suicidal risk independent of depressive symptoms. The relationship of SOC with suicide and suicidal risk has attracted less attention. Low SOC at index attempt in suicide attempters has been found associated with suicidality at 2-month follow-up, and, in line with our findings, the associations were independent of major depression and symptom burden, suggesting that the SOC scale is more than just a mirror of psychopathology ${ }^{47} \mathrm{~A}$ link between low SOC and suicidal ideation and attempts has been also reported in one clinical study ${ }^{48}$ and in some studies with non-clinical populations. ${ }^{49-51}$ Our findings further support the link between sense of coherence and suicidality and provide additional evidence with regard to the validity of both SOC-29 as well as the newly introduced scale for the assessment of suicidality risk, i.e. the RASS.

Strengths of our study include the use of the MINI structured interview for establishing a diagnosis of mental disorder, which was conducted face-to-face with the participant on the same day as the selfreport questionnaires. Also, we used well recognized, standardized instruments for all validity measures, and we recruited patients with established LTCs. Nevertheless, some limitations need to be addressed. It could be argued that a limitation of our study lies in the composition of the "healthy" participant sample, which was recruited from hospital staff and could not be considered representative of the general population. In addition, although mental illness was confirmed by a structured interview, the drawback of using self-report measures for depressive symptom severity, suicidal risk and HRQoL means that we cannot refute the criticism that an underlying response style might have intervened with the results. Finally, the cross-sectional design of the current study precluded the establishment of causal inferences.

In conclusion, the results of the present study showed that the Greek version of the SOC-29 when use as a whole presents a coherent structure with adequate internal consistency and quite satisfactory concurrent and convergent validity. These findings support the applicability of the Greek version of SOC-29 within the Greek population, and future studies could further explore the relevance of SOC-29 with additional scales and outcomes as well as its predictive validity.

\section{Acknowledgements}

The project "ASSessing and Enhancing Resilience To DEPression in people with long term medical conditions in the era of the current Greek social and financial crisis (ASSERT-DEP)" has been co-financed by the European Economic Area (EEA) Financial Mechanism 20092014 (EEA GR07/3767) and National funds as part of the program "Dissimilarity, Inequality and Social Integration" (Grant number: 132324/I4-25/8/2015). The funding source had no involvement in study design; in the collection, analysis and interpretation of data; in the writing of the report; and in the decision to submit the article for publication.

ASSERT-DEP Study Group members are: Katerina Antoniou, Petros Bozidis, Andre F. Carvalho, Foteini Delis, Alexandros A. Drosos, Elspeth Guthrie, Stavros Constantopoulos, Elisavet Ntountoulaki, Vassiliki Paika, Nafsika Poulia, Marianthi Sotiropoulou, Vasilis Tsimihodimos and Thomas Hyphantis (Principal Investigator).

\section{Declarations}

\section{Ethics approval and consent to participate}

a. All study procedures were in accordance with the World Medical Association Helsinki Declaration.

b. The study was approved by the Ioannina Teaching General Hospital hospital's ethics committee (617/17-09-2015).

c. Signed informed consent was obtained from all participants.

\section{Authors' contributions}

All authors were involved in drafting the article or revising it critically for important intellectual content, and all authors approved the final version to be submitted for publication. TH had full access to all of the data in the study and takes responsibility for the integrity of the data and the accuracy of the data analysis. TH, VP, and EN were involved in study conception and design. VP, EN, and DP were involved in acquisition of data. TH, VP, EN, and DP were involved in analysis and interpretation of data.

\section{Conflicts of interest}

Author declares there are no conflicts of interest.

\section{Funding}

None.

\section{References}

1. Antonovsky A. Unraveling the Mystery of Health. Jossey-Bass, San Francisco, USA. 1987 
2. Antonovsky A. The structure and properties of the sense of coherence scale. Soc Sci Med. 1993;36(6):725-733.

3. Eriksson M, Lindström B. Validity of Antonovsky's sense of coherence scale: a systematic review. J Epidemiol Community Health. 2005;59(6):460-466.

4. Langius A, Bjorvell H. [Salutogenic model and use of the (sense of coherence) scale in nursing research--a methodological report]. Vard Nord Utveckl Forsk. 1996;16(1):28-32.

5. Eriksson M, Lindström B. Antonovsky's sense of coherence scale and the relation with health: a systematic review. J Epidemiol Community Health. 2006;60(5):376-381.

6. Eriksson M, Lindström B. Antonovsky's sense of coherence scale and its relation with quality of life: a systematic review. J Epidemiol Community Health. 2007;61(11):938-944.

7. Tan KK, Vehviläinen-Julkunen K, Chan SW. Integrative review: salutogenesis and health in older people over 65 years old. $J$ Adv Nurs. 2014;70(3):497-510.

8. Sjöström N, Hetta J, Waern M. Sense of coherence and suicidality in suicide attempters: a prospective study. J Psychiatr Ment Health Nurs. 2012;19(1):62-69.

9. Winger JG, Adams RN, Mosher CE. Relations of meaning in life and sense of coherence to distress in cancer patients: a meta-analysis. Psychooncology. 2016;25(1):2-10.

10. Sales PM, Carvalho AF, McIntyre RS, et al. Psychosocial predictors of health outcomes in colorectal cancer: a comprehensive review. Cancer Treat Rev. 2014;40(6):800-809.

11. Karalis I, Langius A, Tsirogianni M, et al. The translation-validation of the sense of coherence scale into Greek and its use in primary health care (In Greek with English abstract). Arch Hellenic Med. 2004;21(2):195-203.

12. Aune I, Dahlberg U, Haugan G. Sense of coherence among healthy Norwegian women in postnatal care: Dimensionality reliability and construct validity of the Orientation to Life Questionnaire. Sex Reprod Healthc. 2016;8:6-12.

13. Grevenstein D, Bluemke M, Kroeninger JH. Incremental validity of sense of coherence, neuroticism, extraversion, and general self-efficacy: longitudinal prediction of substance use frequency and mental health. Health Qual Life Outcomes. 2016;14:9.

14. Söderhamn U, Sundsli K, Cliffordson C, et al. Psychometric properties of Antonovsky's 29-item Sense of Coherence scale in research on older home-dwelling Norwegians. Scand J Public Health. 2015;43(8):867-874.

15. Albino J, Shapiro AL, Henderson WG, et al. Validation of the Sense of Coherence Scale in an American Indian population. Psychol Assess. 2016;28(4):386-393.

16. Nawar EW, Niska RW, Xu J. National Hospital Ambulatory Medical Care Survey: 2005 emergency department summary. Adv Data. 2007;386:1-32.

17. Damush TM, Smith DM, Perkins AJ, et al. Risk Factors for Nonelective Hospitalization in Frail and Older Adult, Inner-City Outpatients. Gerontologist. 2007;44(1):68-75.

18. Charlson ME, Pompei P, Ales KL, et al. A new method of classifying prognostic comorbidity in longitudinal studies: development and validation. J Chronic Dis. 1987;40(5):373-383.

19. Callahan LF, Pincus T. The Sense of Coherence scale in patients with rheumatoid arthritis. Arthritis Care Res. 1995;8(1):28- 35.

20. Papadimitriou GN, Beratis S, Matsoukas T, et al. The Greek translation of the Mini International Neuropsychiatric Interview MINI 5.0.0. Dept of Psychiatry of the University of Athens and Patras, Greece. 2004.
21. Sheehan DV, Lecrubier Y, Harnett Sheehan K, et al. The Mini International Neuropsychiatric Interview (M.I.N.I.): the development and validation of a structured diagnostic psychiatric interview for DSMIV and ICD-10. J Clin Psychiatry. 1998;59 (Suppl20):22-33.

22. Hyphantis T, Kotsis K, Voulgari PV, et al. Diagnostic accuracy, internal consistency, and convergent validity of the Greek version of the patien health questionnaire 9 in diagnosing depression in rheumatologic disorders. Arthritis Care Res (Hoboken). 2011;63(9):1313-1321.

23. Hyphantis T, Kroenke K, Papatheodorou E, et al. Validity of the Greek version of the PHQ 15-item Somatic Symptom Severity Scale in patients with chronic medical conditions and correlations with emergency department use and illness perceptions. Compr Psychiatry. 2014;55(8):1950-1959.

24. Hyphantis T, Kotsis K, Kroenke K, et al. Lower PHQ-9 cutpoint accurately diagnosed depression in people with long-term conditions attending the Accident and Emergency Department. J Affect Disord. 2015;176:155-163.

25. Wittkampf KA, Naeije L, Schene AH, et al. Diagnostic accuracy of the mood module of the Patient Health Questionnaire: a systematic review. Gen Hosp Psychiatry. 2007;29(5):388-395.

26. Fountoulakis KN, Pantoula E, Siamouli M, et al. Development of the Risk Assessment Suicidality Scale (RASS): a population-based study. $J$ Affect Disord. 2012;138(3):449-457.

27. Ntountoulaki E, Guthrie E, Kotsis K, et al. Double RASS cutpoint accurately diagnosed suicidal risk in females with long-term conditions attending the emergency department compared to their male counterparts. Compr Psychiatry. 2016;69:193-201.

28. Ginieri Coccossis M, Triantafillou E, Tomaras V, et al. Psychometric properties of WHOQOL-BREF in clinical and health Greek populations: incorporating new culture relevant items. Psychiatriki 2012;23(2):130-142.

29. Altman DG. Practical statistics for medical research. Chapman and Hall, London, UK. 1991. p.285.

30. Frenz AW, Carey MP, Jorgensen RS. Psychometric evaluation of Antonovsky's sense of coherence scale. Psychological Assessment. $1993 ; 5(2): 145-153$.

31. Flannery R, Perry C, Penk WE. Validating Antonovsky's sense of coherence scale. J Clin Psychol. 1994;50:575-577.

32. Larsson G, Kallenberg K. Dimensional analysis of sense of coherence using structural equation modelling. European Journal of Personality. 1999;13(1):51-61.

33. Germano D, Misajon R, Cummins RA. Quality of life and sense of coherence in people with arthritis. Journal of Clinical Psychology in Medical Settings. 2001;8(4):253-261.

34. Dudek B, Makowska Z. Psychometric characteristics of the orientation to life questionnaire for measuring the sense of coherence. Polish Psychological Bulletin. 1993;24:309-318.

35. Sandell R, Blomberg J, Lazar A. The factor structure of Antonovsky's sense of coherence scale in Swedish clinical and nonclinical samples. Personality and Individual Differences. 1998;24:701-711.

36. Bothmer von M, Fridlund B. Self-rated health among university students in relation to sense of coherence and other personality traits. Scand J Caring Sci. 2003;17(4):347-357.

37. Hyphantis TN, Tsifetaki N, Siafaka V, et al. The impact of psychological functioning upon systemic sclerosis patients" quality of life. Semin Arthritis Rheum. 2007;37(2):81-92

38. Bai M, Tomenson B, Creed F, et al. The role of psychological distress and personality variables in the disablement process in rheumatoid arthritis. Scand J Rheumatol . 2009;38(6):419-430. 
39. Hyphantis T, Palieraki K, Voulgari PV, et al. Coping with health-stressors and defence styles associated with health-related quality of life in patients with systemic lupus erythematosus. Lupus. 2011;20(9):893-903.

40. Goulia P, Voulgari PV, Tsifetaki N, et al. Sense of coherence and self-sacrificing defense style as predictors of psychological distress and quality of life in rheumatoid arthritis: a 5-year prospective study. Rheumatol Int. 2015;35(4):691-700.

41. Paika V, Almyroudi A, Tomenson B, et al. Personality variables are associated with colorectal cancer patients" quality of life independent of psychological distress and disease severity. Psychooncology. 2010;19(3):273-282.

42. Hyphantis T, Paika V, Almyroudi A, et al. Personality variables as predictors of early non-metastatic colorectal cancer patients" psychological distress and health-related quality of life: a one-year prospective study. J Psychosom Res. 2011;70(5):411-421.

43. Hyphantis T, Papadimitriou I, Petrakis D, et al. Psychiatric manifestations, personality traits and health-related quality of life in cancer of unknown primary site. Psychooncology. 2013;22(9):2009-2015.

44. Hyphantis T, Goulia P, Zerdes I, et al. Sense of Coherence and Defense Style Predict Sleep Difficulties in Early Non-metastatic Colorectal Cancer. Dig Dis Sci. 2016;61(1):273-282.
45. http: //www.rhpeo.org/ijhp-articles/1998/14/index.htm

46. Nilsson LA. Health promotion as school development. Scandinavian Journal of Nutrition. 2004;48(2):70-76.

47. Sjöström N, Hetta J, Waern M. Sense of coherence and suicidality in suicide attempters: a prospective study. $J$ Psychiatr Ment Health Nurs. 2018;19(1):62-69.

48. Petrie K, Brook R. Sense of coherence, self-esteem depression and hopeless as correlates of re-attempting suicide. Br J Clin Psychol. 1992;31(Pt 3):293-300.

49. Mehlum L. Suicidal ideation and sense of coherence in male conscripts. Acta Psychiatr Scand. 1998;98(6):487-492.

50. Giotakos O. Suicidal ideation, substance use, and sense of coherence in Greek male conscripts. Mil Med. 2003;168(6):447-450.

51. Ristkari T, Sourander A, Helenius H, et al. Sense of coherence among Finnish young men - a cross-sectional study at military call-up. Nord $J$ Psychiatry. 2005;59(6):473-480. 